\title{
Chemotherapy-enhanced inflammation may lead to the failure of therapy and metastasis
}

\author{
This article was published in the following Dove Press journal: \\ OncoTargets and Therapy \\ 12 June 2014 \\ Number of times this article has been viewed
}

\author{
Dinesh Vyas \\ Gieric Laput \\ Arpitak K Vyas \\ College of Human Medicine, Michigan \\ State University, East Lansing, MI, USA
}

Correspondence: Dinesh Vyas

Department of Surgery, Nanomedical

OncoSepsis Laboratory, Institute of

International Health, College of Human

Medicine, Michigan State University,

I200 East Michigan Avenue, Suite 655,

East Lansing, MI 48824, USA

Tel +I 5 I72672460

Email dinesh.vyas@hc.msu.edu
Abstract: The lack of therapy and the failure of existing therapy has been a challenge for clinicians in treating various cancers. Doxorubicin, 5-fluorouracil, cisplatin, and paclitaxel are the first-line therapy in various cancers; however, toxicity, resistance, and treatment failure limit their clinical use. Their status leads us to discover and investigate more targeted therapy with more efficacy. In this article, we dissect literature from the patient perspective, the tumor biology perspective, therapy-induced metastasis, and cell data generated in the laboratory.

Keywords: chemotherapy, cancer, inflammation

\section{Introduction}

Drug resistance and failure remains a major challenge in cancer therapy. Two broad categories have been identified that classify cancer resistance on the basis of response to chemotherapy: primary and acquired. ${ }^{1}$ Although primary resistance precedes initial chemotherapy, acquired resistance involves an accumulation of genetic changes after clinical intervention until tumor cells develop resistance phenotypes. A form of acquired resistance is mediated by the interaction of tumor cells with their microenvironment. ${ }^{1}$ Here, tumor cells circumvent the apoptotic effects of chemotherapy through cell adhesion-mediated resistance, in which tumor cell integrins adhere to fibroblast or the extracellular matrix; ${ }^{2}$ and soluble factor-mediated resistance, which induces the stroma to produce cytokines, chemokines, and growth factors. ${ }^{3-5}$

One developing theme is that not only do chemotherapies induce signaling events that eliminate and control tumor cells but also they stimulate signals that could minimize their clinical efficacy and promote metastatic development. ${ }^{6}$ Advances in our understanding of the molecular mechanisms that elucidate cancer progression and the etiology of drug resistance have identified various crucial targets. Unsurprisingly, some of these targets promote inflammation events and seem to play a role in tumor proliferation, angiogenesis, and metastasis. In this review, we explore four common chemotherapy drugs (cisplatin, paclitaxel, 5-fluorouracil, and doxorubicin) and discuss how each drug induces inflammatory events that may lead to metastasis.

\section{Cisplatin and inflammation}

Cisplatin is one of the most effective anticancer drugs used to treat a variety of solid tumors. ${ }^{7}$ Cisplatin-DNA crosslinks cause cytotoxic lesions in dividing tumor cells; however, the drug's effect on quiescent renal tubular cells is problematic. Many studies indicate that cisplatin-induced renal injury is mediated by oxidative stress, apoptosis, and inflammation. ${ }^{7}$ 
The inflammatory changes play an important role, in particular nuclear factor kappa B (NFkB) and tumor necrosis factor alpha (TNF- $\alpha$ ) signaling pathways. Ohta et al assessed the effects of cisplatin treatment on ovarian cancer cells on NFkB activation and found that cisplatin enhanced its phosphorylation significantly, mediated by the PI3/Akt signaling cascade. ${ }^{8}$ This finding is consistent with the coexpression of NFkB transcription factors p65 and p50 in ovarian cancer patients who received a chemotherapy regimen that included cisplatin. $^{9}$

NFkB signaling is a converging point for controlling downstream signaling cascades that include TNF- $\alpha$, interleukin 1 (IL-1), IL-6, IL-8, and transcription of other inflammatory genes. ${ }^{10-12}$ IL-6 is an important cytokine that regulates angiogenesis, cell proliferation, and invasion. ${ }^{13-16}$ The IL-6 receptor system involves STAT-3- and extracellular signal regulated kinase (ERK)-mediated pathways. ${ }^{17}$ STAT-3 plays multiple roles in cell survival and proliferation through activation of $c-m y c, c y c l i n-D$, and $b c l-2,{ }^{17}$ and persistent activation of STAT-3 is involved in tumorigenesis in a variety of leukemias. ${ }^{18,19}$ Activation of ERK induces cell proliferation through phosphorylation of transcription factors such as c-FOS and ELK $1 .{ }^{20}$ IL- 8 has been implicated in cancer progression, particularly in mediating angiogenesis in various cancer types including melanoma, ${ }^{21}$ pancreatic, ${ }^{22}$ colon, ${ }^{23}$ and non-small-cell lung carcinoma. ${ }^{24}$

TNF- $\alpha$ is also increased after cisplatin treatment, and a variety of pharmacological inhibitors attenuate cisplatin nephrotoxicity mediated by TNF- $\alpha .{ }^{25-27}$ Salicylate treatment on mouse kidneys attenuated cisplatin-induced increase in TNF- $\alpha$ mRNA and also reduced serum TNF- $\alpha$ levels. Rutin treatment on Wistar rats has a beneficial effect on cisplatin's deteriorative effects through inhibition of TNF- $\alpha$ and NFkB pathway-mediated inflammation. Likewise, administration of luteolin in kidneys of mice significantly reduced TNF- $\alpha$ and NFkB, as well as COX-2 expression.

The role of poly (ADP-ribose) polymerase (PARP) proteins has been a target for anticancer therapy. PARP-1 has been implicated in DNA base excision repair, and many studies on PARP inhibitors have explored its antineoplastic profile. Mukhopadhyay et al found that its genetic deletion and pharmacological inhibition attenuates cisplatin-induced

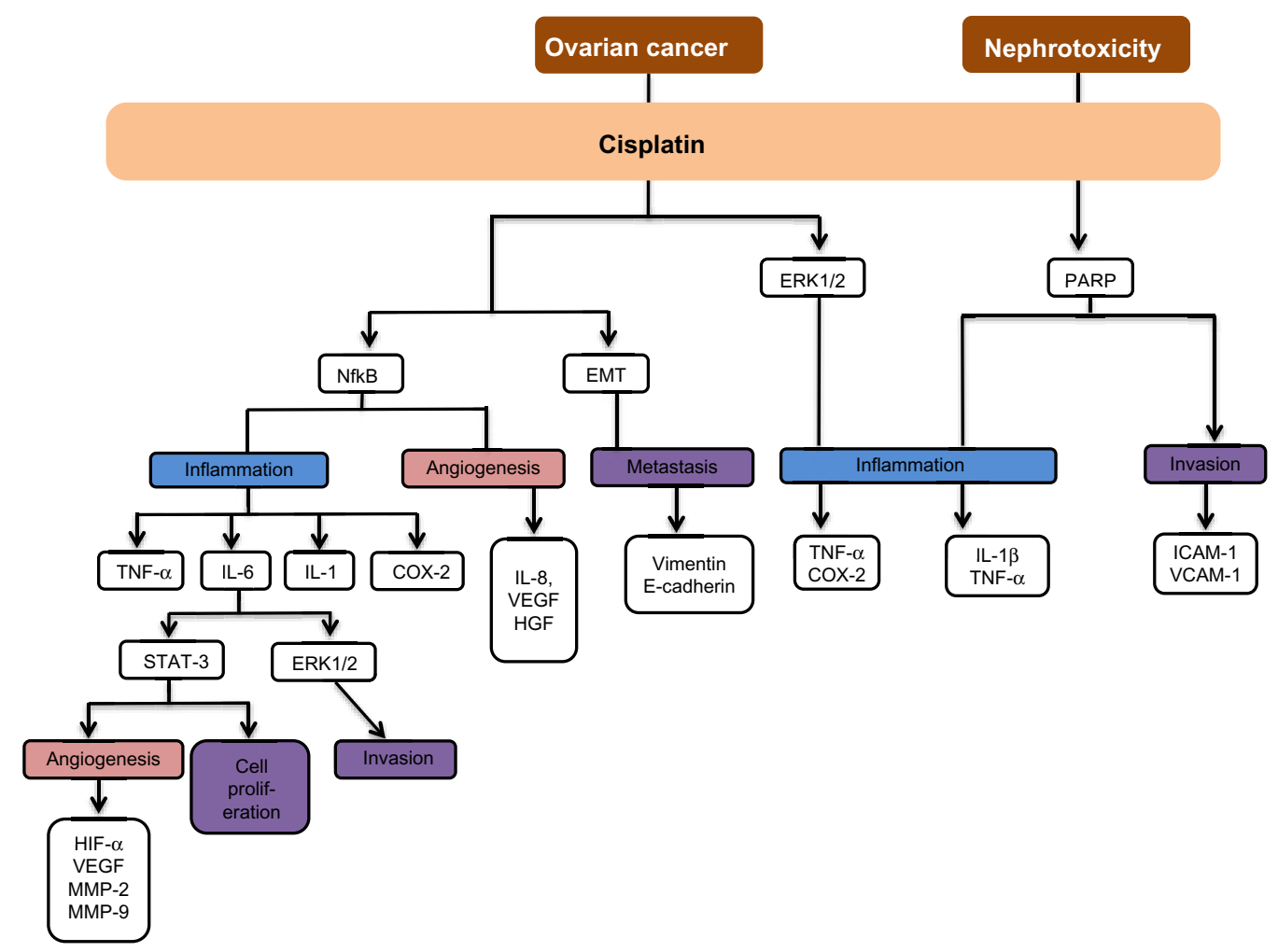

Figure I Cisplatin-induced inflammation is mediated through multiple effectors including activation of NFkB, TNF- $\alpha$, and PARP. NFkB is a focal point for downstream cell survival and proliferation signaling that involves IL-6 and IL-8 upregulation. Cisplatin also induces the MAPK/ERK pathway and EMT acquisition. The ERK signaling cascade is suggested as an upstream signal for TNF- $\alpha$ activation.

Abbreviations: ADP-ribose, poly; COX-2, cyclooxygenase; EMT, epithelial-mesenchymal transition; ERK, mitogen-activated protein kinase; HGF, hepatocyte growth factor; HIF- $\alpha$, hypoxia-inducible factor; ICAM-I, intercellular adhesion molecule; IL, interleukin; MAPK, mitogen-activated protein kinase; MMP, matrix metalloproteinase; NFKB, nuclear factor kappa B; PARP, polymerase; STAT-3, signal transducer and activator of transcription; TNF- $\alpha$, tumor necrosis factor alpha; VCAM-I, vascular cell adhesion molecule; VEGF, vascular endothelial growth factor. 


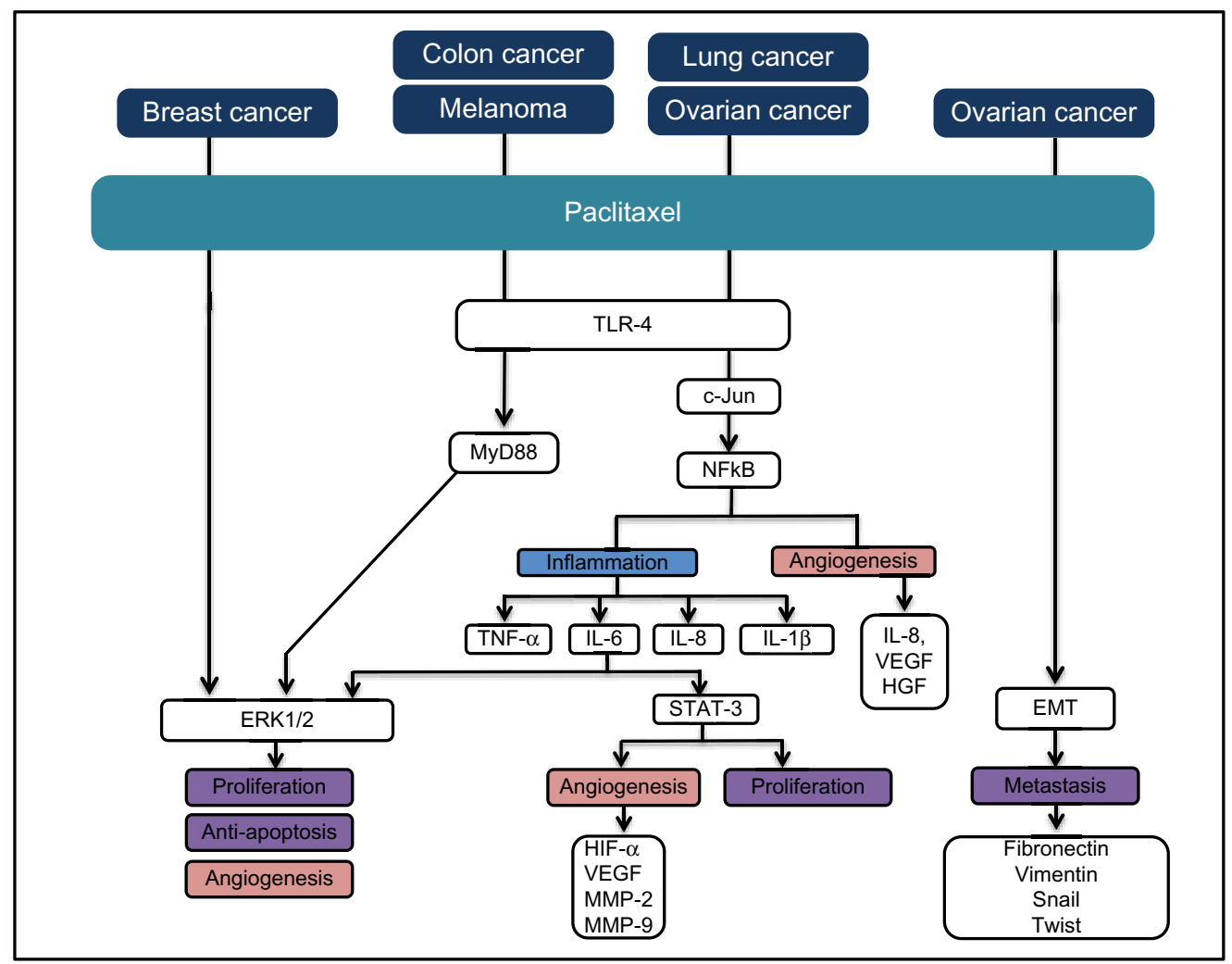

Figure 2 Paclitaxel-induced inflammation is mediated by upregulation of IL-8 via NFKB signaling. In some cancers, paclitaxel has been shown to activate ERK through Tolllike receptor 4 (TLR4)-myeloid differentiation gene 88 (MyD88) signaling. TLR-4 phosphorylates c-Jun (component of activator protein I transcription complex), thereby inducing NFKB activation and upregulation of IL-6, IL-8 and VEGF. Paclitaxel also upregulates metastatic markers consistent with EMT acquisition, including fibronectin, vimentin, Snail, and Twist.

Abbreviations: COX-2, cyclooxygenase; EMT, epithelial-mesenchymal transition; ERK, mitogen-activated protein kinase; HGF, hepatocyte growth factor; HIF- $\alpha$, hypoxiainducible factor; IL, interleukin; MMP, matrix metalloproteinase; NFKB, nuclear factor kappa B; STAT-3, signal transducer and activator of transcription; TNF- $\alpha$, tumor necrosis factor alpha; VEGF, vascular endothelial growth factor.

renal damage and inflammatory response. In this study, cisplatin triggers PARP activation, renal oxidative stress, and inflammatory response. Conversely, administration of PARP inhibitors and PARP-1 knockout mice showed reduced expression of mRNA TNF- $\alpha$ and IL- $1 \beta$, as well as adhesion molecules intracellular adhesion molecule (ICAM)-1 and vascular cellular adhesion molecule (VCAM)-1, and also reduced leukocyte infiltration. ${ }^{28}$

\section{Cisplatin and metastasis}

Several studies have associated cisplatin in inducing prosurvival signaling pathways and markers for invasion, such as the mitogen-activated protein kinase (MAPK), ERK, and acquisition of epithelial-mesenchymal transition (EMT) in cancer.

Genotoxic stress in response to cisplatin causes activation of multiple signal transduction pathways, ${ }^{29,30}$ among which are members of the MAPK pathways. ${ }^{31}$ The MAPK pathway is also implicated in Twist suppression, which sensitizes alveolar cancer cells to cisplatin. ${ }^{32}$ In addition, cisplatin-induced c-Jun N-terminal protein kinase (JNK) and ERK1/2 activation has been demonstrated in ovarian cancer cell lines. ${ }^{33}$ Lee et al showed that cisplatin-resistant ovarian cancer cell lines have high basal levels of nuclear ERK2. ${ }^{34}$ Moreover, inhibition of ERK1/2 has also been shown to sensitize ovarian cancer cells to cisplatin, ${ }^{35}$ implicating a role of ERK1/2 as a mediator in prosurvival signaling in cisplatin-resistant cell lines. Finally, in a recent study, Latifi et $\mathrm{al}^{36}$ assessed the role of EMT in ovarian cancer cells in response to cisplatin. ${ }^{36}$ In this study, cisplatin-induced acquisition of EMT correlated with reduced E-cadherin and increased Vimentin, Snail, Twist, and matrix metalloproteinase (MMP)-2, as well cell surface expression of a variety of cancer stem cell-like markers. ${ }^{36}$

\section{Relationship between cisplatin-induced increase in inflammation and metastasis}

(Figure 1). Although there is evidence of the association between inflammation and metastasis as a result of cisplatin treatment, ${ }^{37}$ the underlying mechanism remains to be elucidated. Several reports suggest that ERK is an upstream signal for the expression of TNF- $\alpha$, prostaglandin, interleukin, and 


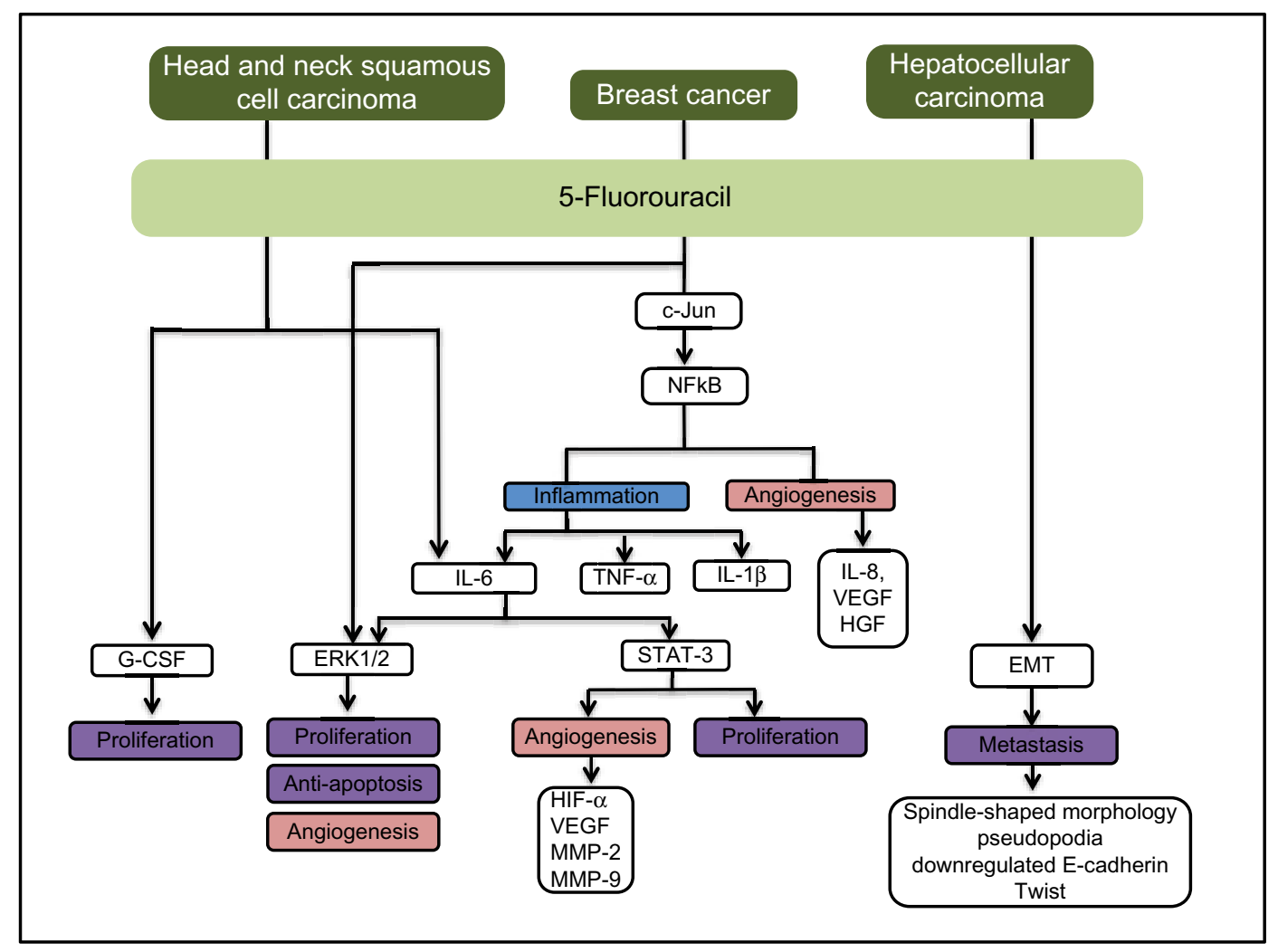

Figure 3 In HNSCC, 5-FU activates G-CSF and IL-6. In breast cancer, 5-FU induces NFKB as well as the mitogen activated protein kinase (MAPK)/extracellular signal regulated kinase (ERK) pathway. Hepatocellular carcinoma cells treated with 5-FU have phenotypes consistent with epithelial-to-mesenchymal transition (EMT) acquisition, including down-regulation of E-cadherin, spindle-shaped morphology, increased pseudopodia formation and upregulation of Twist.

Abbreviations: 5-FU, 5-Fluorouracil, c-Jun, component of the activator protein I transcription complex; EMT, epithelial-mesenchymal transition; ERK, mitogen-activated protein kinase; G-CSF, granulocyte colony-stimulating-factor; HGF, hepatocyte growth factor; HIF- $\alpha$, hypoxia-inducible factor; HNSCC, Head and Neck Squamous Cell Carcinoma; IL, interleukin; MMP, matrix metalloproteinase; NFKB, nuclear factor kappa B; STAT-3, signal transducer and activator of transcription; TNF- $\alpha$, tumor necrosis factor alpha; TWIST, oncogene protein TWIST; VEGF, vascular endothelial growth factor.

COX-2. Inhibition of ERK pathway reduces gene expression of TNF- $\alpha$ in mouse kidney tissue. ${ }^{38}$ In sertoli cells, an ERK inhibitor reduced the cisplatin induction of prostaglandin, interleukin, and COX-2. ${ }^{39}$

\section{Paclitaxel and inflammation}

Paclitaxel, another major drug used to treat solid tumors, ${ }^{40}$ causes apoptosis by overstabilizing microtubules, ${ }^{41}$ leading to cell arrest. ${ }^{42}$ Overall low response to this therapy, especially in breast cancer patients, limits its clinical use, primarily because of recurrence after cessation therapy. ${ }^{43}$ Pathways associated with cell death induced by paclitaxel include phosphorylation of Bcl-2, activation of p53 and cyclin dependent kinases, and activation of the component of the activator protein 1 transcription complex (c-jun) NH2-terminal kinase/ stress-activated protein kinase signaling pathway. ${ }^{44,45}$

A variety of inflammatory mediators and signaling pathways are upregulated in response to paclitaxel administration such as IL- $1 \beta,{ }^{46} \mathrm{IL}-8,{ }^{47} \mathrm{IL}-6,{ }^{48}$ and vascular endothelial growth factor (VEGF)-A. ${ }^{49,50}$ IL-8 expression, in particular, is activated by paclitaxel in ovarian and lung carcinoma cells via activator protein 1 and NFkB promoter sites. ${ }^{47-51}$ Paclitaxel activates Toll-like-receptor $4^{52}$ and other prooncogenic signaling, including NFKB. ${ }^{53}$ These effects are evident in a variety of cancer systems. ${ }^{53-56}$ Rajput et al showed that paclitaxel upregulated cytokine production via Toll-Like-Receptor-4 (TLR-4) in breast cancer cells and that overexpression of TLR-4 is correlated with resistance to the drug by promoting anti-apoptopic proteins. ${ }^{57}$ In addition, many studies show that paclitaxel can induce inflammatory cytokine production in murine macrophages cell lines and in human PBMCs, which is most likely related to its ability to mimic bacterial lipopolysaccharide. ${ }^{58,59}$

\section{Paclitaxel and metastasis}

Several studies also report the induction of markers for invasion and metastasis as a result of paclitaxel administration. Paclitaxel induces activation of the MEK/ ERK pathway in human breast cancer ${ }^{60}$ and lymphoma. ${ }^{61}$ 


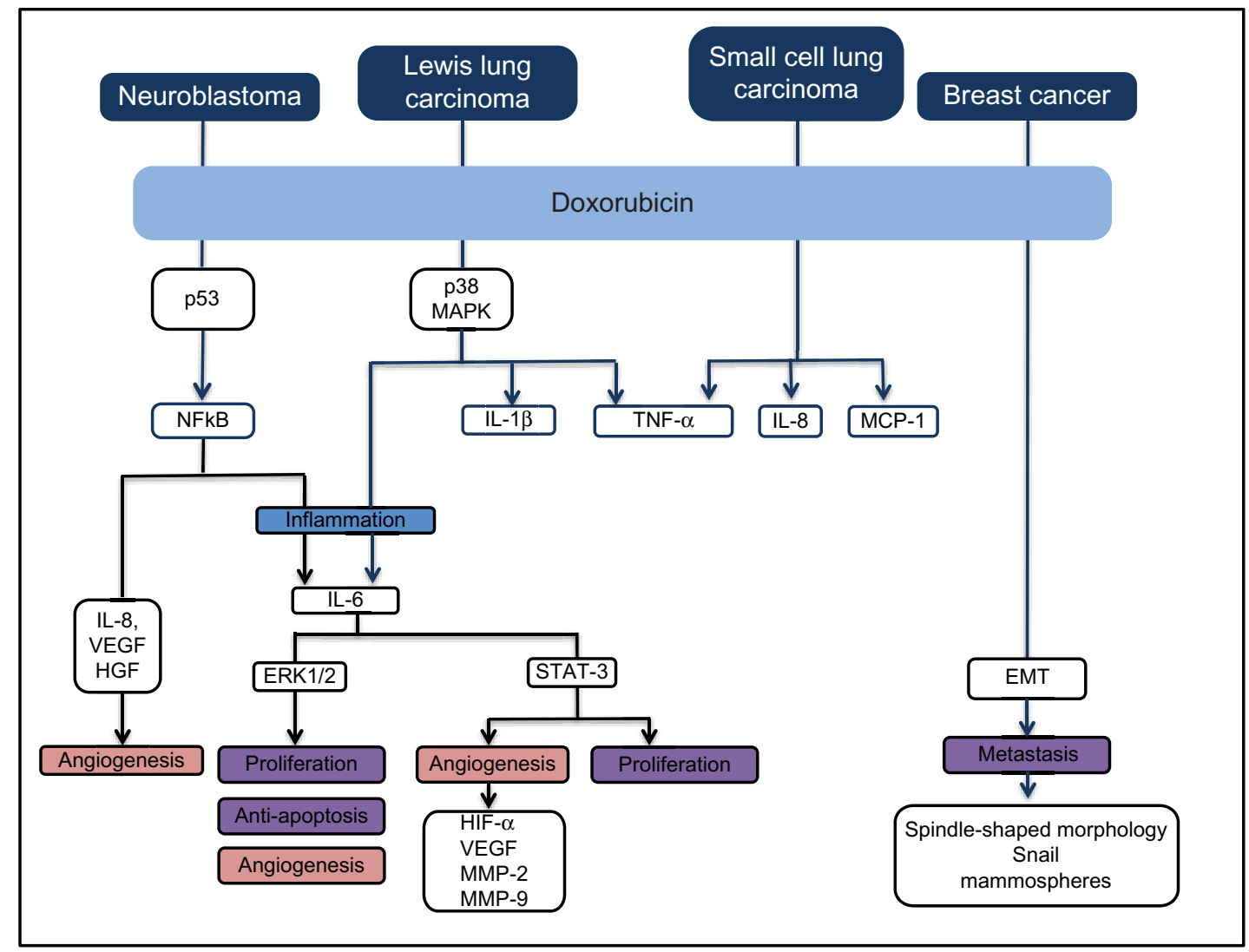

Figure 4 Doxorubicin-induced inflammation in a variety of cancers includes upregulation of NFKB, IL-I $\beta$, IL-6, IL-8, TNF- $\alpha$ and monocyte chemoattractant protein I (MCP-I). In neuroblastoma cells, p533 is required for doxorubicin to activate NFKB. In Lewis lung carcinoma, IL-I $\beta$ and IL-6 are upregulated by the p38/MAPK pathway. Doxorubicin induces EMT acquisition in breast cancer.

Abbreviations: EMT, epithelial-mesenchymal transition; ERK, mitogen-activated protein kinase; HGF, hepatocyte growth factor; HIF- $\alpha$, hypoxia-inducible factor; IL, interleukin; MAPK, mitogen activated protein kinase; MMP, matrix metalloproteinase; NFKB, nuclear factor kappa B; STAT-3, signal transducer and activator of transcription; TNF- $\alpha$, tumor necrosis factor alpha; VEGF, vascular endothelial growth factor.

Taxman et al showed that paclitaxel increases the expression of multiple genes that are important in proliferation, adhesion, and metastasis, such as chemokine IL-8 and EGF-like growth factors. ${ }^{6}$ In particular, the melanoma growth stimulating activity/growth-related oncogene 1 (MGSA/Gro1), a gene linked to melanoma growth and transformation and that is a marker for melanoma metastasis, is increased by paclitaxel and is reduced by an MEK inhibitor. These findings provide evidence that paclitaxel coordinately targets a group of genes with crucial global effects on the tumor cell.

Kajiyama et $\mathrm{al}^{62}$ also investigated the effects of paclitaxel treatment of epithelial ovarian carcinoma on cellular functions such as cell motility, invasive ability, and proliferative potential. Consistent with EMT acquisition, epithelial-ovarian cancer cell line (NOS2-PR) cells showed spindle-shaped morphology and enhanced pseudopodia formation. In addition, a decreased expression of E-cadherin and an increased expression in mesenchymal markers such as fibronectin, vimentin, smooth muscle actin, and EMT regulatory factors
Snail and Twist were observed. A marked enhancement of migratory potential in wound assay and metastatic potential to the peritoneum of mice was also evident. ${ }^{62}$

\section{Connection between paclitaxel- induced increase in inflammation and metastasis}

(Figure 2). Recent studies indicate that the expression of TLR-4, its adaptor protein MyD88, and the activation of ERK signaling pathways are inextricably linked with tumor growth, progression, invasion, and chemoresistance. Wu et al showed that paclitaxel activated the TLR-4-MyD88-ERK signaling pathway. ${ }^{63}$ Another study demonstrated that the inhibition of ERK signaling potentiates paclitaxel-induced apoptosis in human colon cancer cells. In ovarian cancer cell lines, paclitaxel binding to TLR-4 induced cJun phosphorylation, activated the NFKB pathway, and induced the production of IL-8, IL-6, VEGF, and monocyte chemotactic protein $1 .^{64}$ Conversely, silencing of TLR-4 with siRNA resulted in downregulation of cJun phosphorylation and chemoresistance. ${ }^{65}$ 


\section{5-Fluorouracil and inflammation}

5-Fluorouracil (5-FU), another commonly used antineoplastic drug, leads to the misincorporation of fluoronucleotides into RNA and DNA and to the inhibition of the nucleotide synthetic enzyme thymidylate synthase. It is used to treat a variety of cancers, including colorectal cancers and breast cancers. ${ }^{66} \mathrm{How}-$ ever, its clinical use is hampered because of drug resistance ${ }^{67}$ and induction of intestinal damage, referred to as intestinal mucositis, the most significant dose-limiting toxicity. ${ }^{68,69}$

Studies in animal and human models have established evidence of changes in proinflammatory cytokine levels after administration of 5-FU. Logan et al showed that tissue and serum levels of NFאB, TNF- $\alpha$, IL-1 $\beta$, and IL- 6 in rats were elevated after 5 -FU administration before histological evidence of tissue damage. ${ }^{70}$

Another recent study by Reers et al demonstrated complex cytokine changes in the tumor microenvironment in eight different cell lines of patients with squamous cell cancer of the head and neck. ${ }^{71}$ In this study, although no evidence of changes in IL-8 secretion was observed, low doses of 5-FU stimulated the secretions of IL-6 and granulocyte colonystimulating-factor (G-CSF) on all screened squamous cell cancer of the head and neck cell lines. However, sublethal concentrations of 5-FU revealed a dose-dependent decrease in IL-1 $\beta$. Concerning G-CSF and TNF- $\alpha$ secretion in primary tumors versus metastatic cell lines, G-CSF and TNF- $\alpha$ were increased in primary tumors at low doses of 5-FU, whereas a sharp decrease in secretion was evident in the metastases. Another recent study has investigated the inflammatory effects of 5-FU chemotherapy in bone, which can result in osteopenia and osteoporosis. Supplementation with Emu oil, a substance known to have a potent anti-inflammatory effect, demonstrated suppression of 5-FU-induced expression of $\mathrm{TNF}-\alpha$ and an osteoclast activator of NFKB. ${ }^{72}$

\section{5-FU and metastasis}

Several reports have shown that 5-FU treatment results in activation of markers for invasion and metastasis. Elsea et al demonstrated that clinically relevant doses of cytotoxic chemotherapy drugs, including 5-FU, activate the p38 MAPK pathway in murine macrophages. ${ }^{73} \mathrm{~A}$ recent study has implicated a mechanistic role for EMT in elucidating 5-FU chemoresistance in human hepatocellular carcinoma cell lines (HLF-R). Uchibori et al found that after treatment with 5-FU, HLF-R cell lines showed a decreased number of apoptotic cells and had morphologic phenotypes consistent with EMT acquisition, such as spindle-shaped morphology, increased pseudopodia formation, and loss of cell-cell adhesion. ${ }^{74}$ In addition, 5-FU treatment also downregulated E-cadherin gene expression and induced Twist gene expression in HLF-R cells. Genes associated with 5-FU metabolism such as ribonucleotide reductases and multidrug resistance protein 5 were also downregulated and upregulated, respectively, providing further evidence that 5-FU metabolism plays a role in 5-FU-induced EMT acquisition.

\section{Connection between 5-FU-induced inflammation and metastasis}

(Figure 3). Several reports have explored the interplay between the induction of markers for invasion and inflammation as a result of 5-FU administration. As stated earlier, findings from Elsea et al showed that 5-FU treatment activated the MAPK pathway in murine macrophages. ${ }^{73} \mathrm{In}$ this study, 5-FU-induced activation of MAPK activity was associated with increased production of IL-1 $\beta$, IL-6, and TNF- $\alpha$. Addition of an inhibitor of p38 MAPK blocked the accumulation of IL-1 $\beta$, IL- 6 , and TNF- $\alpha$, demonstrating that 5 -FU-induced inflammatory cytokine production is dependent on p38 MAPK. ${ }^{73}$ A recent study by Vinod et al also showed that 5-FU treatment upregulates NFkB, MAPK pathway, and thymidylate synthase in breast cancer cell lines and demonstrated that there is cross-talk between NFкB, MAPK pathway, and thymidylate synthase as a result of 5-FU-induced signaling events. ${ }^{75}$

\section{Doxorubicin and inflammation}

Doxorubicin is used for hematologic and solid tumors; ${ }^{76,77}$ however, its major limitation is cardiotoxicity, ${ }^{78}$ cardiomyopathy, and congestive heart failure ${ }^{79,80}$ through partially understood mechanisms.

Doxorubicin treatment induces inflammation in various cancer cell lines (eg, urothelial cells on exposure to doxorubicin show an increase in prostaglandin E2 and IL-1 $).{ }^{81}$ Similarly, studies have shown that high IL- $8,{ }^{82,83} \mathrm{NF} \kappa \mathrm{B}$, TNF- $\alpha,{ }^{82,84}$ monocyte chemotactic protein-1 (MCP-1), ${ }^{83}$ and G-CSF ${ }^{84}$-expressing mice have better outcomes from doxorubicin-induced mortality and cardiac damage if they are pretreated with an IL-1 receptor antagonist. ${ }^{85}$

Doxorubicin-mediated activation of NFKB and inflammatory cytokines has been shown with doxorubicin effect on adipose tissue, thereby increasing serum total cholesterol, triglyceride, and low-density lipoprotein levels. ${ }^{86-88}$ This can be explained by doxorubicin induced downregulation of peroxisome proliferator activated receptor gamma, which is present in white adipose tissue. ${ }^{89-93}$ The sequence of events can be summarized as a reduction in circulating free fatty 
acid clearance, ${ }^{94-96}$ macrophage recruitment, ${ }^{97}$ and activation of NFKB and inflammatory cytokines. ${ }^{98,99}$

\section{Doxorubicin and metastasis}

Doxorubicin induces production of transforming growth factor beta, leading to EMT acquisition in human MDAMB-231. ${ }^{100}$ Doxorubicin-induced transforming growth factor beta production enhances Smad2 and Smad3 phosphorylation, causing tumor cell migration and invasion, suggesting a role in EMT-associated signaling. Doxorubicin also induced spindle-shaped morphology and increased nuclear translocation of Snail, suggestive of EMT phenotypic characteristics in breast cancer cells.

\section{Connection between doxorubicin-induced increase in inflammation and metastasis}

(Figure 4). In neuroblastoma cell lines, doxorubicin-induced p53 activation is essential for subsequent NFKB activation. ${ }^{101}$ In murine macrophages, exposure to doxorubicin resulted in significant increase in IL-1 $\beta$ and IL-6 mRNA expression and this pathway is mediated by p38 MAPK, suggesting a role for p38 MAPK in the induction of inflammatory cytokines. ${ }^{73}$

\section{Disclosure}

The authors report no conflicts of interest in this work.

\section{References}

1. Meads MB, Gatenby RA, Dalton WS. Environment-mediated drug resistance: a major contributor to minimal residual disease. Nat Rev Cancer. 2009;9(9):665-674.

2. Cordes N, Seidler J, Durzok R, Geinitz H, Brakebusch C. beta1-integrinmediated signaling essentially contributes to cell survival after radiationinduced genotoxic injury. Oncogene. 2006;25(9):1378-1390.

3. Bisping G, Leo R, Wenning D, et al. Paracrine interactions of basic fibroblast growth factor and interleukin-6 in multiple myeloma. Blood. 2003;101(7):2775-2783.

4. Bisping G, Wenning D, Kropff M, et al. Bortezomib, dexamethasone, and fibroblast growth factor receptor 3-specific tyrosine kinase inhibitor in t $(4 ; 14)$ myeloma. Clin Cancer Res. 2009;15(2):520-531.

5. Lin B, Podar K, Gupta D, et al. The vascular endothelial growth factor receptor tyrosine kinase inhibitor PTK787/ZK222584 inhibits growth and migration of multiple myeloma cells in the bone marrow microenvironment. Cancer Res. 2002;62(17):5019-5026.

6. Taxman DJ, MacKeigan JP, Clements C, Bergstralh DT, Ting JP. Transcriptional profiling of targets for combination therapy of lung carcinoma with paclitaxel and mitogen-activated protein/extracellular signal-regulated kinase kinase inhibitor. Cancer Res. 2003;63(16): 5095-5104.

7. Yao X, Panichpisal K, Kurtzman N, Nugent K. Cisplatin nephrotoxicity: a review. Am J Med Sci. 2007;334(2):115-124.

8. Ohta T, Ohmichi M, Hayasaka T, et al. Inhibition of phosphatidylinositol 3-kinase increases efficacy of cisplatin in in vivo ovarian cancer models. Endocrinology. 2006;147(4):1761-1769.
9. Annunziata CM, Stavnes HT, Kleinberg L, et al. Nuclear factor kappaB transcription factors are coexpressed and convey a poor outcome in ovarian cancer. Cancer. 2010;116(13):3276-3284.

10. Foo SY, Nolan GP. NF-kappaB to the rescue: RELs, apoptosis and cellular transformation. Trends Genet. 1999;15(6):229-235.

11. Tornatore L, Thotakura AK, Bennett J, Moretti M, Franzoso G. The nuclear factor kappa B signaling pathway: integrating metabolism with inflammation. Trends Cell Biol. 2012;22(11):557-566.

12. Solinas G, Karin M. JNK1 and IKKbeta: molecular links between obesity and metabolic dysfunction. FASEB J. 2010;24(8):2596-2611.

13. Hirano T, Nakajima K, Hibi M. Signaling mechanisms through gp130: a model of the cytokine system. Cytokine Growth Factor Rev. 1997;8(4): 241-252.

14. Kortylewski M, Heinrich PC, Mackiewicz A, et al. Interleukin-6 and oncostatin M-induced growth inhibition of human A375 melanoma cells is STAT-dependent and involves upregulation of the cyclin-dependent kinase inhibitor p27/Kip1. Oncogene. 1999;18(25):3742-3753.

15. Nakajima K, Yamanaka Y, Nakae K, et al. A central role for Stat3 in IL-6-induced regulation of growth and differentiation in M1 leukemia cells. EMBO J. 1996;15(14):3651-3658.

16. Hirano T, Ishihara K, Hibi M. Roles of STAT3 in mediating the cell growth, differentiation and survival signals relayed through the IL-6 family of cytokine receptors. Oncogene. 2000;19(21):2548-2556.

17. Kojima H, Inoue T, Kunimoto H, Nakajima K. IL-6-STAT3 signaling and premature senescence. JAKSTAT. 2013;2(4):e25763.

18. Yu H, Pardoll D, Jove R. STATs in cancer inflammation and immunity: a leading role for STAT3. Nat Rev Cancer. 2009;9(11):798-809.

19. Bowman T, Garcia R, Turkson J, Jove R. STATs in oncogenesis. Oncogene. 2000;19(21):2474-2488.

20. Avruch J, Zhang XF, Kyriakis JM. Raf meets Ras: completing the framework of a signal transduction pathway. Trends Biochem Sci. 1994;19(7):279-283.

21. Singh S, Varney M, Singh RK. Host CXCR2-dependent regulation of melanoma growth, angiogenesis, and experimental lung metastasis. Cancer Res. 2009;69(2):411-415.

22. Matsuo Y, Raimondo M, Woodward TA, et al. CXC-chemokine/ CXCR2 biological axis promotes angiogenesis in vitro and in vivo in pancreatic cancer. Int J Cancer. 2009;125(5):1027-1037.

23. Ning Y, Manegold PC, Hong YK, et al. Interleukin-8 is associated with proliferation, migration, angiogenesis and chemosensitivity in vitro and in vivo in colon cancer cell line models. Int J Cancer. 2011;128(9): 2038-2049.

24. Arenberg DA, Kunkel SL, Polverini PJ, Glass M, Burdick MD, Strieter RM. Inhibition of interleukin-8 reduces tumorigenesis of human non-small cell lung cancer in SCID mice. J Clin Invest. 1996;97(12): 2792-2802.

25. Arjumand W, Seth A, Sultana S. Rutin attenuates cisplatin induced renal inflammation and apoptosis by reducing NF $\kappa \mathrm{B}, \mathrm{TNF}-\alpha$ and caspase-3 expression in wistar rats. Food Chem Toxicol. 2011;49(9): 2013-2021.

26. Domitrović R, Cvijanović O, Pugel EP, Zagorac GB, Mahmutefendić H, Škoda M. Luteolin ameliorates cisplatin-induced nephrotoxicity in mice through inhibition of platinum accumulation, inflammation and apoptosis in the kidney. Toxicology. 2013;310:115-123.

27. Ramesh G, Reeves WB. Salicylate reduces cisplatin nephrotoxicity by inhibition of tumor necrosis factor-alpha. Kidney Int. 2004;65(2): 490-499.

28. Mukhopadhyay $\mathrm{P}$, Horváth $\mathrm{B}$, Kechrid M, et al. Poly(ADP-ribose) polymerase-1 is a key mediator of cisplatin-induced kidney inflammation and injury. Free Radic Biol Med. 2011;51(9):1774-1788.

29. Mabuchi S, Ohmichi M, Nishio Y, et al. Inhibition of NFkappaB increases the efficacy of cisplatin in in vitro and in vivo ovarian cancer models. J Biol Chem. 2004;279(22):23477-23485.

30. Leong CO, Vidnovic N, DeYoung MP, Sgroi D, Ellisen LW. The p63/ p73 network mediates chemosensitivity to cisplatin in a biologically defined subset of primary breast cancers. J Clin Invest. 2007;117(5): $1370-1380$. 
31. Brozovic A, Osmak M. Activation of mitogen-activated protein kinases by cisplatin and their role in cisplatin-resistance. Cancer Lett. 2007;251(1):1-16.

32. Zhuo WL, Wang Y, Zhuo XL, Zhang YS, Chen ZT. Short interfering RNA directed against TWIST, a novel zinc finger transcription factor, increases A549 cell sensitivity to cisplatin via MAPK/ mitochondrial pathway. Biochem Biophys Res Commun. 2008;369(4): 1098-1102.

33. Cui W, Yazlovitskaya EM, Mayo MS, Pelling JC, Persons DL. Cisplatin-induced response of c-jun N-terminal kinase 1 and extracellular signal - regulated protein kinases 1 and 2 in a series of cisplatinresistant ovarian carcinoma cell lines. Mol Carcinog. 2000;29(4): 219-228.

34. Lee S, Yoon S, Kim DH. A high nuclear basal level of ERK2 phosphorylation contributes to the resistance of cisplatin-resistant human ovarian cancer cells. Gynecol Oncol. 2007;104(2):338-344.

35. Hayakawa J, Ohmichi $M$, Kurachi $H$, et al. Inhibition of BAD phosphorylation either at serine 112 via extracellular signal-regulated protein kinase cascade or at serine 136 via Akt cascade sensitizes human ovarian cancer cells to cisplatin. Cancer Res. 2000;60(21): 5988-5994.

36. Latifi A, Abubaker K, Castrechini N, et al. Cisplatin treatment of primary and metastatic epithelial ovarian carcinomas generates residual cells with mesenchymal stem cell-like profile. J Cell Biochem. 2011;112(10):2850-2864.

37. Guerrero-Beltrán CE, Mukhopadhyay P, Horváth B, et al. Sulforaphane, a natural constituent of broccoli, prevents cell death and inflammation in nephropathy. J Nutr Biochem. 2012;23(5):494-500.

38. Jo SK, Cho WY, Sung SA, Kim HK, Won NH. MEK inhibitor, U0126, attenuates cisplatin-induced renal injury by decreasing inflammation and apoptosis. Kidney Int. 2005;67(2):458-466.

39. Yamaguchi K, Ishikawa T, Kondo Y, Fujisawa M. Cisplatin regulates Sertoli cell expression of transferrin and interleukins. Mol Cell Endocrinol. 2008;283(1-2):68-75.

40. Rowinsky EK. The development and clinical utility of the taxane class of antimicrotubule chemotherapy agents. Annu Rev Med. 19948: 353-374.

41. Schiff PB, Fant J, Horwitz SB. Promotion of microtubule assembly in vitro by taxol. Nature. 1979;277(5698):665-667.

42. Horwitz SB. Taxol (paclitaxel): mechanisms of action. Ann Oncol. 1995;Supp1 6:S3-S6.

43. Gradishar WJ, Tjulandin S, Davidson N, et al. Phase III trial of nanoparticle albumin-bound paclitaxel compared with polyethylated castor oil-based paclitaxel in women with breast cancer. J Clin Oncol. 2005;23(31):7794-7803.

44. Lee LF, Li G, Templeton DJ, Ting JP. Paclitaxel (Taxol)-induced gene expression and cell death are both mediated by the activation of c-Jun NH2-terminal kinase (JNK/SAPK). J Biol Chem. 1998;273(43): 28253-28260.

45. Meikrantz W, Schlegel R. Suppression of apoptosis by dominant negative mutants of cyclin-dependent protein kinases. $J$ Biol Chem. 1996;271(17):10205-10209.

46. White CM, Martin BK, Lee LF, Haskill JS, Ting JP. Effects of paclitaxel on cytokine synthesis by unprimed human monocytes, T lymphocytes, and breast cancer cells. Cancer Immunol Immunother. 1998;46(2): 104-112.

47. Lee LF, Haskill JS, Mukaida N, Matsushima K, Ting JP. Identification of tumor-specific paclitaxel (Taxol)-responsive regulatory elements in the interleukin-8 promoter. Mol Cell Biol. 1997;17(9):5097-5105.

48. Pusztai L, Mendoza TR, Reuben JM, et al. Changes in plasma levels of inflammatory cytokines in response to paclitaxel chemotherapy. Cytokine. 2004;25(3):94-102.

49. Volk LD, Flister MJ, Bivens CM, et al. Nab-paclitaxel efficacy in the orthotopic model of human breast cancer is significantly enhanced by concurrent anti-vascular endothelial growth factor A therapy. Neoplasia. 2008;10(6):613-623.
50. Volk LD, Flister MJ, Chihade D, Desai N, Trieu V, Ran S. Synergy of nab-paclitaxel and bevacizumab in eradicating large orthotopic breast tumors and preexisting metastases. Neoplasia. 2011;13(4):327-338.

51. Collins TS, Lee LF, Ting JP. Paclitaxel up-regulates interleukin-8 synthesis in human lung carcinoma through an NF-kappaB- and AP-1-dependent mechanism. Cancer Immunol Immunother. 2000;49(2): 78-84.

52. Zimmer SM, Liu J, Clayton JL, Stephens DS, Snyder JP. Paclitaxel binding to human and murine MD-2. J Biol Chem. 2008;283(41): 27916-27926.

53. Zaks-Zilberman M, Zaks TZ, Vogel SN. Induction of proinflammatory and chemokine genes by lipopolysaccharide and paclitaxel (Taxol) in murine and human breast cancer cell lines. Cytokine. 2001;15(3): 156-165.

54. Pei Z, Lin D, Song X, Li H, Yao H. TLR4 signaling promotes the expression of VEGF and TGFbeta1 in human prostate epithelial PC3 cells induced by lipopolysaccharide. Cell Immunol. 2008;254(1):20-27.

55. Silasi DA, Alvero AB, Illuzzi J, et al. MyD88 predicts chemoresistance to paclitaxel in epithelial ovarian cancer. Yale J Biol Med. 2006;79(3-4): 153-163.

56. Tang XY, Zhu YQ, Wei B, Wang H. Expression and functional research of TLR4 in human colon carcinoma. Am J Med Sci. 2010;339(4): 319-326.

57. Rajput S, Volk-Draper LD, Ran S. TLR4 is a novel determinant of the response to paclitaxel in breast cancer. Mol Cancer Ther. 2013;12(8): $1676-1687$.

58. Manthey CL, Qureshi N, Stütz PL, Vogel SN. Lipopolysaccharide antagonists block taxol-induced signaling in murine macrophages. J Exp Med. 1993;178(2):695-702.

59. Moos PJ, Muskardin DT, Fitzpatrick FA. Effect of taxol and taxotere on gene expression in macrophages: induction of the prostaglandin $\mathrm{H}$ synthase-2 isoenzyme. J Immunol. 1999;162(1):467-473.

60. Shtil AA, Mandlekar S, Yu R, et al. Differential regulation of mitogenactivated protein kinases by microtubule-binding agents in human breast cancer cells. Oncogene. 1999;18(2):377-384.

61. Lieu CH, Liu CC, Yu TH, Chen KD, Chang YN, Lai YK. Role of mitogen-activated protein kinase in taxol-induced apoptosis in human leukemic U937 cells. Cell Growth Differ. 1998;9(9):767-776.

62. Kajiyama H, Shibata K, Terauchi M, et al. Chemoresistance to paclitaxel induces epithelial-mesenchymal transition and enhances metastatic potential for epithelial ovarian carcinoma cells. Int J Oncol. 2007;31(2):277-283.

63. Wu J, Guan M, Wong PF, Yu H, Dong J, Xu J. Icariside II potentiates paclitaxel-induced apoptosis in human melanoma A375 cells by inhibiting TLR4 signaling pathway. Food Chem Toxicol. 2012;50(9): 3019-3024.

64. Xu R, Sato N, Yanai K, et al. Enhancement of paclitaxel-induced apoptosis by inhibition of mitogen-activated protein kinase pathway in colon cancer cells. Anticancer Res. 2009;29(1):261-270.

65. Szajnik M, Szczepanski MJ, Czystowska M, et al. TLR4 signaling induced by lipopolysaccharide or paclitaxel regulates tumor survival and chemoresistance in ovarian cancer. Oncogene. 2009;28(49): 4353-4363.

66. Sonis ST. Mucositis as a biological process: a new hypothesis for the development of chemotherapy-induced stomatotoxicity. Oral Oncol. 1998;34(1):39-43.

67. Longley DB, Harkin DP, Johnston PG. 5-fluorouracil: mechanisms of action and clinical strategies. Nat Rev Cancer. 2003;3(5):330-338.

68. Baerg J, Murphy JJ, Anderson R, Magee JF. Neutropenic enteropathy: a 10-year review. J Pediatr Surg. 1999;34(7):1068-1071.

69. Bowen JM, Gibson RJ, Cummins AG, Keefe DM. Intestinal mucositis: the role of the Bcl-2 family, $\mathrm{p} 53$ and caspases in chemotherapy-induced damage. Support Care Cancer. 2006;14(7):713-731.

70. Logan RM, Stringer AM, Bowen JM, Gibson RJ, Sonis ST, Keefe DM. Serum levels of NFkappaB and pro-inflammatory cytokines following administration of mucotoxic drugs. Cancer Biol Ther. 2008;7(7): 1139-1145. 
71. Reers S, Pfannerstill AC, Rades D, et al. Cytokine changes in response to radio-/chemotherapeutic treatment in head and neck cancer. Anticancer Res. 2013;33(6):2481-2489.

72. Raghu Nadhanan R, Abimosleh SM, Su YW, Scherer MA, Howarth GS, Xian CJ. Dietary emu oil supplementation suppresses 5-fluorouracil chemotherapy-induced inflammation, osteoclast formation, and bone loss. Am J Physiol Endocrinol Metab. 2012;302(11):E1440-E1449.

73. Elsea CR, Roberts DA, Druker BJ, Wood LJ. Inhibition of p38 MAPK suppresses inflammatory cytokine induction by etoposide, 5-fluorouracil, and doxorubicin without affecting tumoricidal activity. PLoS One. 2008;3(6):e2355

74. Uchibori K, Kasamatsu A, Sunaga M, et al. Establishment and characterization of two 5-fluorouracil-resistant hepatocellular carcinoma cell lines. Int J Oncol. 2012;40(4):1005-1010.

75. Vinod BS, Antony J, Nair HH, et al. Mechanistic evaluation of the signaling events regulating curcumin-mediated chemosensitization of breast cancer cells to 5-fluorouracil. Cell Death Dis. 2013;4:e505.

76. Blum RH, Carter SK. Adriamycin. A new anticancer drug with significant clinical activity. Ann Intern Med. 1974;80(2):249-259.

77. Takemura G, Fujiwara H. Doxorubicin-induced cardiomyopathy from the cardiotoxic mechanisms to management. Prog Cardiovasc Dis. 2007;49(5):330-352.

78. Von Hoff DD, Layard MW, Basa P, et al. Risk factors for doxorubicininduced congestive heart failure. Ann Intern Med. 1979;91(5):710-717.

79. Yen HC, Oberley TD, Vichitbandha S, Ho YS, St Clair DK The protective role of manganese superoxide dismutase against adriamycin-induced acute cardiac toxicity in transgenic mice. J Clin Invest. 1996;98(5):1253-1260.

80. Kang YJ, Chen Y, Epstein PN. Suppression of doxorubicin cardiotoxicity by overexpression of catalase in the heart of transgenic mice. J Biol Chem. 1996;271(21):12610-12616.

81. Kang SH, Chess-Williams R, Anoopkumar-Dukie S, McDermott C. Induction of inflammatory cytokines and alteration of urothelial ATP, acetylcholine and prostaglandin E2 release by doxorubicin. Eur $J$ Pharmacol. 2013;700(1-3):102-109.

82. Niiya M, Niiya K, Kiguchi T, et al. Induction of TNF-alpha, uPA, IL-8 and MCP-1 by doxorubicin in human lung carcinoma cells. Cancer Chemother Pharmacol. 2003;52(5):391-398.

83. Shibakura M, Niiya K, Kiguchi T, et al. Induction of IL-8 and monoclyte chemoattractant protein-1 by doxorubicin in human small cell lung carcinoma cells. Int J Cancer. 2003;103(3):380-386.

84. Sauter KA, Wood LJ, Wong J, Iordanov M, Magun BE. Doxorubicin and daunorubicin induce processing and release of interleukin-1 $\beta$ through activation of the NLRP3 inflammasome. Cancer Biol Ther. 2011;11(12):1008-1016.

85. Zhu J, Zhang J, Xiang D, et al. Recombinant human interleukin-1 receptor antagonist protects mice against acute doxorubicin-induced cardiotoxicity. Eur J Pharmacol. 2010;643(2-3):247-253.

86. Koti BC, Vishwanathswamy AH, Wagawade J, Thippeswamy AH. Cardioprotective effect of lipistat against doxorubicin induced myocardial toxicity in albino rats. Indian J Exp Biol. 2009;47(1):41-46.
87. Iliskovic N, Singal PK. Lipid lowering: an important factor in preventing adriamycin-induced heart failure. Am J Pathol. 1997;150(2): 727-734.

88. Venkatesan N, Venkatesan P, Karthikeyan J, Arumugam V. Protection by taurine against adriamycin-induced proteinuria and hyperlipidemia in rats. Proc Soc Exp Biol Med. 1997;215(2):158-164.

89. Jiang G, Dallas-Yang Q, Li Z, et al. Potentiation of insulin signaling in tissues of Zucker obese rats after acute and long-term treatment with PPARgamma agonists. Diabetes. 2002;51(8):2412-2419.

90. Laplante M, Sell H, MacNaul KL, Richard D, Berger JP, Deshaies Y. PPAR-gamma activation mediates adipose depot-specific effects on gene expression and lipoprotein lipase activity: mechanisms for modulation of postprandial lipemia and differential adipose accretion. Diabetes. 2003;52(2):291-299.

91. Oakes ND, Thalén PG, Jacinto SM, Ljung B. Thiazolidinediones increase plasma-adipose tissue FFA exchange capacity and enhance insulin-mediated control of systemic FFA availability. Diabetes. 2001;50(5):1158-1165.

92. Arunachalam S, Kim SY, Kim MS, et al. Adriamycin inhibits adipogenesis through the modulation of PPAR $\gamma$ and restoration of adriamycinmediated inhibition of adipogenesis by PPAR $\gamma$ over-expression. Toxicol Mech Methods. 2012;22(7):540-546.

93. Arunachalam S, Tirupathi Pichiah PB, Achiraman S. Doxorubicin treatment inhibits PPAR $\gamma$ and may induce lipotoxicity by mimicking a type 2 diabetes-like condition in rodent models. FEBS Lett. 2013;587(2):105-110.

94. Lim HJ, Lee S, Lee KS, et al. PPARgamma activation induces CD36 expression and stimulates foam cell like changes in rVSMCs. Prostaglandins Other Lipid Mediat. 2006;80(3-4):165-174

95. Schoonjans K, Peinado-Onsurbe J, Lefebvre AM, et al. PPARalpha and PPARgamma activators direct a distinct tissue-specific transcriptional response via a PPRE in the lipoprotein lipase gene. EMBO J. 1996;15(19):5336-5348.

96. Lemberger T, Desvergne B, Wahli W. Peroxisome proliferator-activated receptors: a nuclear receptor signaling pathway in lipid physiology. Annu Rev Cell Dev Biol. 1996;12:335-363.

97. Shi H, Kokoeva MV, Inouye K, Tzameli I, Yin H, Flier JS. TLR4 links innate immunity and fatty acid-induced insulin resistance. J Clin Invest. 2006;116(11):3015-3025.

98. Nguyen MT, Favelyukis S, Nguyen AK, et al. A subpopulation of macrophages infiltrates hypertrophic adipose tissue and is activated by free fatty acids via Toll-like receptors 2 and 4 and JNK-dependent pathways. J Biol Chem. 2007;282(48):35279-35292.

99. Cusi K. The role of adipose tissue and lipotoxicity in the pathogenesis of type 2 diabetes. Curr Diab Rep. 2010;10(4):306-315.

100. Bandyopadhyay A, Wang L, Agyin J, et al. Doxorubicin in combination with a small TGFbeta inhibitor: a potential novel therapy for metastatic breast cancer in mouse models. PLoS One. 2010;5(4):e10365.

101. Armstrong MB, Bian X, Liu Y, et al. Signaling from p53 to NF-kappa B determines the chemotherapy responsiveness of neuroblastoma. Neoplasia. 2006;8(11):964-974.
OncoTargets and Therapy

\section{Publish your work in this journal}

OncoTargets and Therapy is an international, peer-reviewed, open access journal focusing on the pathological basis of all cancers, potential targets for therapy and treatment protocols employed to improve the management of cancer patients. The journal also focuses on the impact of management programs and new therapeutic agents and protocols on

\section{Dovepress}

patient perspectives such as quality of life, adherence and satisfaction. The manuscript management system is completely online and includes a very quick and fair peer-review system, which is all easy to use. Visit http://www.dovepress.com/testimonials.php to read real quotes from published authors. 